\title{
What Do We Need to Improve Communication Skills Training in China: Suggestions from Nationwide Survey
}

\section{Yurong Ge ( $\square$ 825829353@qq.com )}

People's Hospital of Ningxia Hui Autonomous Region

\section{Yuko Takeda}

Juntendo University

\section{Peifeng Liang}

People's Hospital of Ningxia Hui Autonomous Region

\section{Shilin Xia}

the First Affiliated Hospital of Dalian Medical University

\section{Marcellus Nealy \\ Juntendo University \\ Yoko Muranaka \\ Juntendo University \\ Shishu Sun \\ Juntendo University \\ Takao Okada \\ Juntendo University}

\section{Research Article}

Keywords: Simulated patient, Medical Education, Communication, doctor-patient relationship

Posted Date: September 13th, 2021

DOl: https://doi.org/10.21203/rs.3.rs-805798/v1

License: (1) This work is licensed under a Creative Commons Attribution 4.0 International License.

Read Full License 


\section{What do we need to improve communication skills training in China: suggestions from nationwide survey}

Yurong Ge ${ }^{\mathrm{a},}$, Yuko Takeda ${ }^{\mathrm{b}}$, Peifeng Liang ${ }^{\mathrm{c}}$, Shilin $\mathrm{Xia}^{\mathrm{d}}$ Marcellus Nealy ${ }^{\mathrm{e}}$, Yoko Muranaka ${ }^{\mathrm{f}}$, Shishu Sun ${ }^{\mathrm{b}}$, Takao Okada

a Department of Teaching affairs, The First Affiliated Hospital Northwest University for Nationalities, Yinchuan, China; People's Hospital of Ningxia Hui Autonomous Region, Yinchuan, China

${ }^{\mathrm{b}}$ Department of Medical Education, Juntendo University, Tokyo, Japan

c Department of Medical Statistics, People's Hospital of Ningxia Hui Autonomous Region, Yinchuan, China

${ }^{\mathrm{d}}$ Clinical Laboratory of Integrative Medicine, the First Affiliated Hospital of Dalian Medical University, Dalian, China

e General Education, Juntendo University, Tokyo, Japan

${ }^{\mathrm{f}}$ Graduate School of Health Care and Nursing, Juntendo University, Chiba, Japan

* Corresponding author: Yurong Ge

Email: 825829353@qq.com

Telephone: 18809589817

Corresponding address: Department of Teaching affairs, The First Affiliated Hospital Northwest University for Nationalities, Yinchuan, China; People's Hospital of Ningxia Hui Autonomous Region, Yinchuan, China 


\section{Abstract}

Background: To investigate the current status of simulated patient (SP) program education in mainland China.

Methods: It is a cross sectional surveys to SP program with qualitative research method and statistical analysis. The study was conducted in 79 medical colleges in mainland China. Questionnaires were distributed to 79 medical colleges in mainland China, and 68 were completed and returned. Of those, we selected 64 valid feedback (valid response rate $81.0 \%$ ). We compared the current status of SP, the origin of SP, SP training course, challenge, and future plan of 79 medical colleges in mainland China.

Results: The number of SP program education in medical college with long clinical programs was significantly higher than that in medical colleges with single 5-year clinical program $(\mathrm{p}<0.01)$. Communication training accounted for $72.9 \%$ in SP program education, while the proportion was $90 \%$ in those colleges that planned to initiate SP program education. SP recruitment included students (56.8\%), residents (48.7\%), medical staffs (32.4\%) and teachers (32.4\%). The colleges, planning a SP program, preferred teachers $(80 \%)$ and students (55\%). In OSCE, a co-scoring from both SPs and teachers occupied a higher proportion in interrogation station and doctor-patient communication station. The obstacles were SP team instability, insufficient fund, lack of evaluation criterion, and few courses. 
Conclusions: SP program has advantage of improving doctor-patient relationship. Patient and public involvement will benefit from an increase for resident proportion in SP members. Overcoming the obstacles contributes to expanding the utilization of SP program and further improving student's communication skills.

Keywords: Simulated patient; Medical Education; Communication; doctor-patient relationship

\section{Background}

The modern system of medical education, through continual innovation, aims to promote the level of patient-centered medical service. Barrow HS, a neurology expert at the University of Southern California Berkley, firstly reported the simulated patient (SP) program applied in medical education since the 1960s[1]. After repeated practice in SP training, students obtained an opportunity to polish their professional medical technique in a real clinical environment by using a feedback from SP. The mode of SP facilitates the development of medical education, which contributes to the improvement of medical care. Nowadays SP plays an increasingly important role in the medical education[2-4].

In 1991, Paula L. Stillman introduced SP into China[5]. After that Chinese medical educators widely used SP program during education. In Chinese hospital and medical campus, educators performed SP program education in education of various clinical disciplines, including internal medicine, psychiatry, traditional Chinese medicine, and nursing education[6-9]. In 2003, Chan et al reported that significant improvement in communication skills among Chinese doctors could be achieved through training that 
involved role-play and feedback using SP[10]. In 2015, Zhang et al. revealed a significant improvement in the OSCE scores of students who participated in simulated training, which also included the use of SP[11]. These reports support the notion that the positive impact of SP based education in Chinese context. Currently, violence against doctors, such as verbal abuse and physical attacks, has become a concern in China[12]. This problem has partly been ascribed to miscommunication between patients and their doctors, which could be due to a lack of training of practical communication skills[13].

In 2016,we conducted a nationwide questionnaire survey to study the effect underlying SP program education in the amelioration of doctor-patient communication. We exhibited the basal information of SP, such as composition and categories. Moreover, we described the challenging issues and future SP implementation. Our findings from this questionnaire survey provide insights for the benefit of SP program education in communication skill training(CST).

\section{Methods}

\section{Data collection}

Based on the email contact and phone confirmation, we assigned the questionnaire to 79 medical colleges in mainland China.We conducted a questionnaire survey for a period of one month in October 2016. Eleven schools declined participation due to the lack of SP programs at their institutions. As a result, we received 68 feedbacks (response rate $86.1 \%$ ). Of those, we selected 64 valid feedback (valid response rate $81.0 \%)$ 
These colleges in China include two length at the time of clinical education systems: one is single 5-year clinical program, the other processes long clinical programs with 5-year, 7-year or 8-year clinical learning. Medical students obtain a graduate degree in long clinical program after a 7- or 8-year course and bachelor's degree after a 5-year clinical program studying.

\section{Questionnaire design}

Based on SP series questionnaire survey raised by Abe[14,15], we drew a draft of questionnaire. this draft was appraised and revised by a statistician and six education experts from Japan and China. We conducted a pre-survey in $10 \mathrm{SP}$ training teachers from Northwest University for Nationalities and Ningxia Medical University, both of which had an experience of SP program education.

The main elements in the questionnaire were the current status of SP, the origin of SP, SP training course, challenge, and future plan. The questionnaire consisting of binary response items (YES/NO), multiple-choice questions, and subjective response. The item without option answer triggered a subjective response, which was analyzed using qualitative research methods.

\section{Statistical analysis}

The data collected from the survey was statistically processed using SPSS 20 (SPSS, Inc., Chicago, IL, USA). Qualitative data was expressed as frequency and percent. Chi-square test or Fisher's Exact Test were used for $2 \times 2$ qualitative variables. $p<0.05$ was considered to indicate a statistically significant difference. 


\section{Results}

\section{Test for the questionnaire}

Cronbach's $\alpha$ for the questionnaire was 0.76 , indicating that it demonstrated good reliability.

\section{SP characteristics in medical education}

Of the 64 colleges who responded, 37 colleges (58\%) carried out SP program education.Depending on the length of the medical program, participation of SP in medical courses varied (Table 1) as did the number of years each university worked with SP (Table 2). Table 2 compared the duration of SP training between 5-year clinical program college and long clinical program college. More colleges with long year program instituted SP program education for more than a decade $(p<0.001)$. Of the 12 universities with longer programs that have been working with SP for more than 10 years, 4 have been using SP participation for 15 years or longer. All universities working with SP for more than 10 years have a school history of more than 60 years.

At the time of the survey, a total of 1004 people participated as SP in the responding schools, of which, 438 were male $(43.6 \%)$ and 566 were female $(56.4 \%)$. Figure 1 illustrates the types of people recruited as SP; 21 colleges $(56.8 \%)$ recruited students, 
while local residents were recruited at 18 colleges $(48.7 \%)$, Medical staffs and teachers also play the roles of SP at $32.4 \%$ of medical schools.

Figure 2 presented that the main types of SP program were interrogation $(78.4 \%)$, OSCE (75.7\%), and doctor-patient communication (72.9\%). In OSCE test showed in Figure 3, SPs and examiners gave a co-sore for students' performance in interrogation station (48.6\%), doctor-patient communication station (45.9\%), and physical examination (29.7\%). Only a small number of colleges gave SP's score without examiners evaluation.

Table 1. The quantity of S medical colleges with or without SP program $(n=64)$

\begin{tabular}{lll}
\hline Time length of clinical program & SP program $[\mathrm{n}(\%)]$ & No SP program $[\mathrm{n}(\%)]$ \\
\hline 5 years & $20(45.5)$ & $24(54.5)$ \\
5 -8 years & $17(85.0)$ & $3(15.0)$ \\
\hline
\end{tabular}

$\chi^{2}=8.816 \mathrm{p}<0.01$

Table 2. Time length of SP program implementation $(n=37)$

\begin{tabular}{lll}
\hline Time length of clinical program & Less than 10 years [n (\%)] & 10 years or above $[\mathrm{n}(\%)]$ \\
\hline 5 years & $19(95.0)$ & $1(0.5)$ \\
& $5(29.4)$ & $12(70.6)$ \\
\hline
\end{tabular}

Fisher's Exact Test: $\mathrm{p}<0.01$ 


\section{SP training and quality evaluation}

Regarding SP training, of the 64 institutions that responded, 28 colleges (44\%) had a department responsible for SP training, The training was delivered mostly by lectures as well as field observation, demonstrations, videos, and practice exercises.

Thirty-seven universities practiced assessment of SP performance, which included feedback from faculty $(73.0 \%)$, student feedback $(70.3 \%)$, self-designed scale (29.7\%). In addition, some colleges without quality evaluation accounted for $16.2 \%$ in 37 medical colleges. Thirty-one of the 37 universities (84\%) responded that they were satisfied with the performance of current SP.

\section{Challenges and future plans in SP implementation}

The most challenging issues cited were "retention" (72.9\%) followed by "lack of budget" (51.4\%) and "lack of evaluation standards" (45.9\%) (Fig. 4). Meanwhile, some response revealed that there was few standardized training course.

However, 20 colleges (74\%) indicated a desire to establish one in the future especially for "Communication" and "Physical examination" training programs (Fig. 5)。 Besides, $18(90 \%) \quad$ colleges preferred to enable SP practice in doctor-patient communication and physical examination (Fig 5). When asked about prerequisites for establishing SP programs at their respective universities, 18 (90\%) colleges indicated a need for budget and SP trainers. 16(80\%) colleges stated the need of college support, SP training curriculum, and SP candidates. When asked who they would consider as an 
SP candidate, the most common response was faculty $(80 \%)$, followed by general public, medical personnel, or students (55\%, respectively).

Among 27 colleges without education programs involving SP, 7 universities (25.9\%) said they were not planning to utilize SP for education in the future. The reasons given included lack of support, budget, trainers, recruitment strategies, set curriculum, and expert cooperation.

\section{Discussion}

Based on 79 feedbacks of questionnaire, we presented an investigation into the status and problem of SP, which was the first survey for medical colleges with long clinical program in China. The questionnaire recovery rate exceeded $80 \%$. This survey presented that more than half colleges $(58 \%)$ performed SP program education, and Yang ${ }^{16}$ investigated the situation of SP teaching in 80 medical institutions in China. Although the respondents were different, $60 \%$ of the medical institutions engaged in SP teaching were close to the survey results of this study.It can be told from these two surveys that SP program in China was widely applied into medical education. In these college with SP program education, the teaching content and training mode in this survey were in accordance with those in Yang's survey[16].

Although SP has been widely used in China, The current survey found that student and teacher in medical college had a majority in SP member. and medical educators have a high degree of satisfaction with the current work of SP. Most colleges, with the 
coming SP program, planned to recruit medical student and teacher.Although using students and faculty may be cost-effective, this practice may reduce the realism of the training and limit the potential effectiveness ${ }^{4}$.An appropriate manner would be to increase the proportion of resident, who were neither in campus nor in medical organization. Under the guidance of the patient-centered medical philosophy proposed by the world health organization (WHO), the medical and educational communities in various countries continuously advocate the participation of patients and the public in medical care, education and research(Patient and public involvement: PPI)[17]. The education and training of communication skills has relied on SP participating in teaching and training through testimonials about their own experience[17], and students and faculty is difficult to meet this requirement.especially in the doctor-patient communication in teaching of medical students listen to the Patient's conversation is very important.Therefore.it is suggested that SP in China should reduce the proportion of recruiting students and teachers, and attract more citizens to participate in the teaching, and improve the effect of SP's participation in teaching.

Nowadays there are many medical disputes and violent affairs in China. The medical violence does not only particularly occur in China or Japan, but also in India, Pakistan, and Nepal[12,18]. Previous studies showed that SP program is available for the improvement of medical education[19,20]. A research of four European countries showed that the medical education in these countries improved the communication skills with SP program[21]. In Asia, medical education in Japan exemplify a good utilization of SP in medical education, which was mainly based on doctor-patient 
communication[15]. Our survey in China demonstrated that communication teaching in SP program education hold a high proportion in medical college. Besides, this proportion was even higher in colleges planning SP education. It can thus be suggested that medical colleges in China attach great importance to CST and look forward to the role of SP in communication education between doctors and patients.

From this survey, we observed the status and character of SP training, meanwhile we also found some obstacles to the development and implementation of SP program education. In OSCE test, almost half of colleges provided student assessment from both examiner and SP. According to the professional clinical operation, examiners gave students their score. While, the score from SP appeared to reflect student's performance in CST through patient experience. Barry Wight reported a positive association between examiner's and SP's score in OSCE test[22]. Effective score given by SP benefited from a SP's feedback to medical student in normal exercise, suggesting that SP's feedback is important for the student's CST[23]. The hardest part in medical education, how SP's feedback to students accorded with the objectives of medical education, depended on the quality of SP training[16]. The effectiveness and appropriateness of SP training attribute to establish an evaluation criterion and a series of standardized courses. An evaluation criterion enables SP member to be acted as a standard simulated patient after all training courses, instead of subjective feedback from student or teacher. There has been a standard training course in Japan, not yet in China[24]. These findings seem to suggest that medical colleges in China 
shall pay more attention to SP training, including course and criteria of SP. This is also mentioned in the research results of Yang[16].

Now, SP program education is in need of college's support, recruiting strategy, professional trainer, and adequate budget. The work in demand will help involvement of SP, stability of SP team, and effectiveness of SP program education. We need to approach the issue in order to improve the medical environment gradually, providing a reference for other countries with serious problem of doctor-patient relationship.

\section{Conclusion}

We provided solid data to demonstrate the status of SP in medical education. In China, medical colleges widely used SP program, which had much value in CST. SP program looked forward to improving doctor-patient relationship. SP program education should recruit resident instead of student or teacher, in order to realize PPI. We concluded some obstacles to the development of SP program education and gave several suggestions, providing a reference for countries with similar problems.

\section{Declarations}

\section{Ethics approval and consent to participate}

Before the investigation, we applied for ethics review from both Juntendo University School of Medicine in Japan and the First Affiliated Hospital Northwest University for Nationalities in China. We were informed that approval was not necessarily due to the nature of the study. With regard to consent to participate, an additional file shows this in more detail [see Additional file 1], the purpose of the survey was stated in an 
email, which was directly sent to the participants. The participants chose whether or not to respond without any penalty. In addition, they were informed that filling out of the survey was considered to be the same as giving consent.

\section{Consent for publication}

Not applicable.

\section{Availability of data and materials}

Not applicable.

\section{Competing interests}

Not applicable.

\section{Funding}

This research is supported by Fundamental Research Funds for the Central Universities of Northwest University for Nationalities (Grant No. 31920140071).

\section{Contributors}

YG designed the questionnaire, contacted the participants, organized the study. YT co-developed the questionnaire, interpret study results, and finalized the manuscript. PL designed the web based survey, statistically analyzed the data. MN prepared the manuscript. YM advised the study design and structure of the manuscript. TO advised the study design and structure of the survey.

\section{Acknowledgements}

The authors would like to thank Dr. Yoon Soo Park for his critical review and valuable advice on preparing this manuscript. 


\section{References}

1. Barrows HS, Abrahamson S: The programmed patient:a technique for appraising Clinical performance in clinical neurology. Med Educ 1964;39:802-805.

2. Howley LD: Standardized patient practices: initial report on the survey of US and Canadian medical schools. Med Educ Online 2009;14:7-10.

3. Abe K: A nationwide survey of standardized patients: who they are, what they do, and how they experience their work. Patient Educ Couns 2011;84:261-264. doi:10.1016 j.pec.2010.07.017

4. Cleland J, Abe K, Rethans J: The use of simulated patients in medical education:

AMEE Guide No 42. Medical Teacher 2009;31:477-486.

5. Stillman PL, Sawyer WD: A new program to enhance the teaching and assessment of clinical skills in the People's Republic of China. Acad Med 1992; 67:495-499.

6. Shen J, Liu JJ: Application of Clinical Teaching With SP in Teaching of Internal Medicine Probation Clinical Teaching. Continuing Medical Education. 2015;29:29-30.

7. Xue HY, Cheng WW, Kong FY: Application of standardized patients in clinical practice teaching of psychiatry. China Medical Herald 2019;16:89-92.

8. Liu C, Zhang YY, Zhang HL: Research and Practice of Student Standardized Patient Combining Simulated Wards in Teaching of TCM Surgery. Chinese Journal of Information on TCM 2017;24:117-120.

9. Sun TM, Guo Y: The Application of Standardized Patient Case-based Teaching in Nursing Practice Teaching of Cardiac Surgery. China Continuing Medical Education 20 19;11:18-20.

10. Chan CS,Wun YT, Cheng A: Communication skill of general practitioners: any roo m for improvement? How much can it be improved? BMC Med Ed 2003;37:514-526.

11. Zhang MY, Cheng $\mathrm{X}, \mathrm{Xu} \mathrm{AD}$ : Clinical simulation training improves the clinical per formance of Chinese medical students. Med Educ Online 2015;20:87-96.

12. Hesketh $\mathrm{T}, \mathrm{Wu} \mathrm{D}$, Mao L: Violence against doctors in China. BMJ 2012;345:34-44.

13. Yin K, Huang Y, Wilkes MS: Teaching communication skills to undergraduate medical students in China. Med Teach 2016;38:63-69.

14. Abe K, Ban N: Standardized patient survey in the US.

[https://www1.gifu-u.ac.jp/ medc/sp/spsurvey.htm.] Accessed on 15 Jan 2021.

15. Toshiro S, Fumihito Y, Akinobu Y.A: Survey on Training of Simulated and Standardized Patients ( SP ) and SP Program in Undergraduate Medical Education in Japan. Medical Education 2011;1:29-35 . 
16. Yang HX, Yuan X, Nai XL: Standardized patient methodology in mainland China: a nationwide survey. $B M C$ Med Edu 2019;19:214-220 .

17. Jonathan Q, Tritter BA: Revolution or evolution: the challenges of conceptualizing patient and public involvement in a consumerist world. Health Expectations 2009;12:275-287.

18. Ambesh P: Violence against doctors in the Indian subcontinent: A rising bane. Indian Heart 2016;68:749-750.

19. Bernard M, de Roten Y, Despland JN: Oncology clinicians' defenses and adherence to communication skills training with simulated patients: an exploratory study. Canc. Educ 2012; 27:399-403.

20. Bolstad AL, Xu Y, Shen JJ: Reliability of standardized patients used in a communication study on international nurses in the United States of America. Nurs Health Sci 2012;14:67-73.

21. Debra N, Diana $\mathrm{T}$, Tanya $\mathrm{T}$ : Key challenges in simulated patient programs: An international comparative case study. BMC Medical Education 2011;11:69-79.

22. Wright B, McKendree J, Morgan L, Allgar VL, Brown A: Examiner and simulated patient ratings of empathy in medical student final year clinical examination: are they useful? $B M C$ Medical Education 2014;14:199-207.

23. Bahreman NT, Swoboda SM.: Honoring diversity: developing culturally competent communication skills through simulation.Nurs. Educ 2016;55:105-108.

24. Toshiro Shimura, Fumihito Yoshii, Akinobu Yoshimura: Training Curriculum for Simulated and Standardized Patients: The 16th Medical Simulation Committee of the Japan Society for Medical Education. Medical Education 2012;43:33-36.

\section{Additional files}

Additional file 1: Investigate and study informed consent. pdf.

Corresponding author :Yurong Ge

E-mai1 : 825829353@qq.com 
Figures

\section{Fig.1 Types of SP member $(n=37)$}

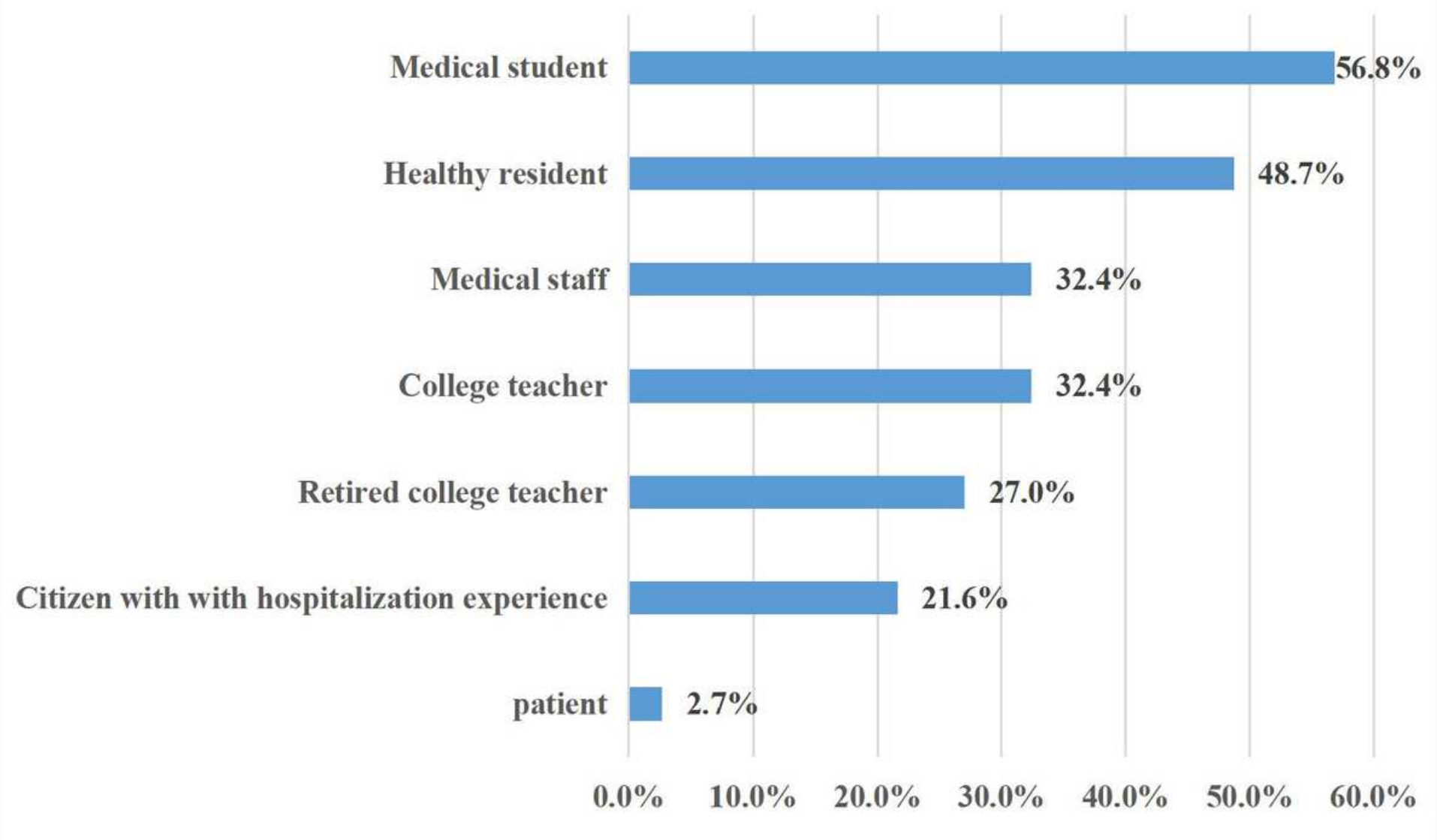

Figure 1

See image above for figure legend 
Figer2 Types of SP Progarams $(n=37)$

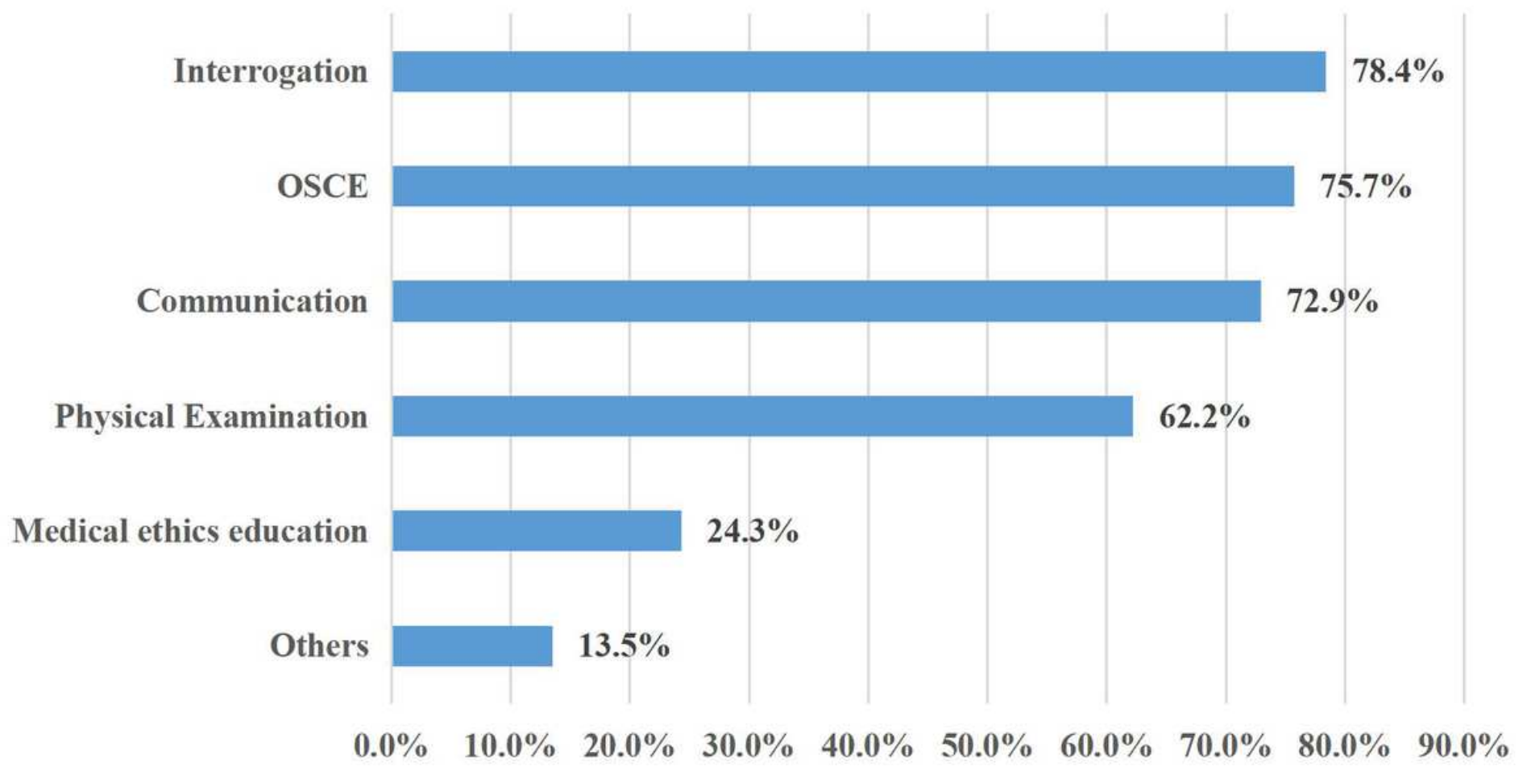

\section{Figure 2}

See image above for figure legend

Fig.3 Categories of OSCE Evaluators( $(n=37)$

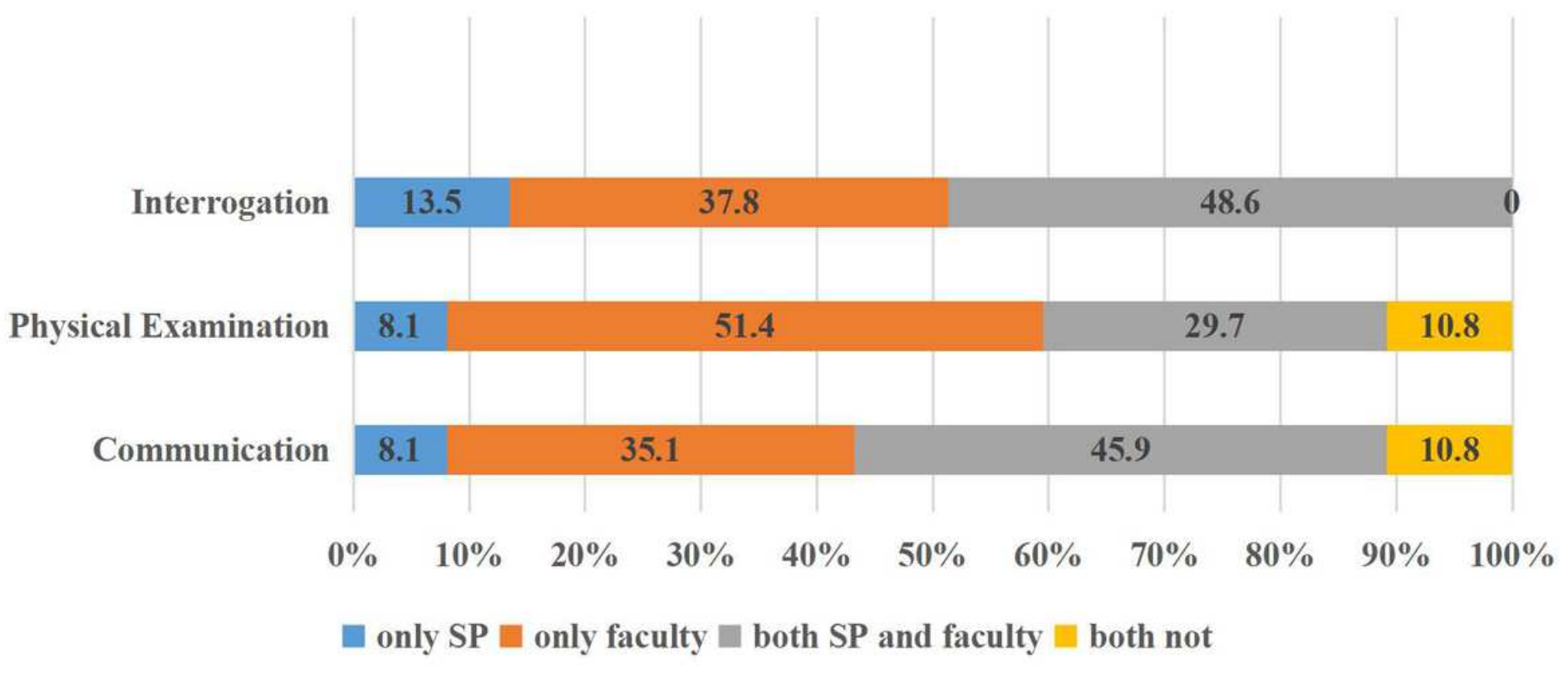


See image above for figure legend

Fig. 4 Challenging Issues in Implementing SP Based Program $(n=37)$

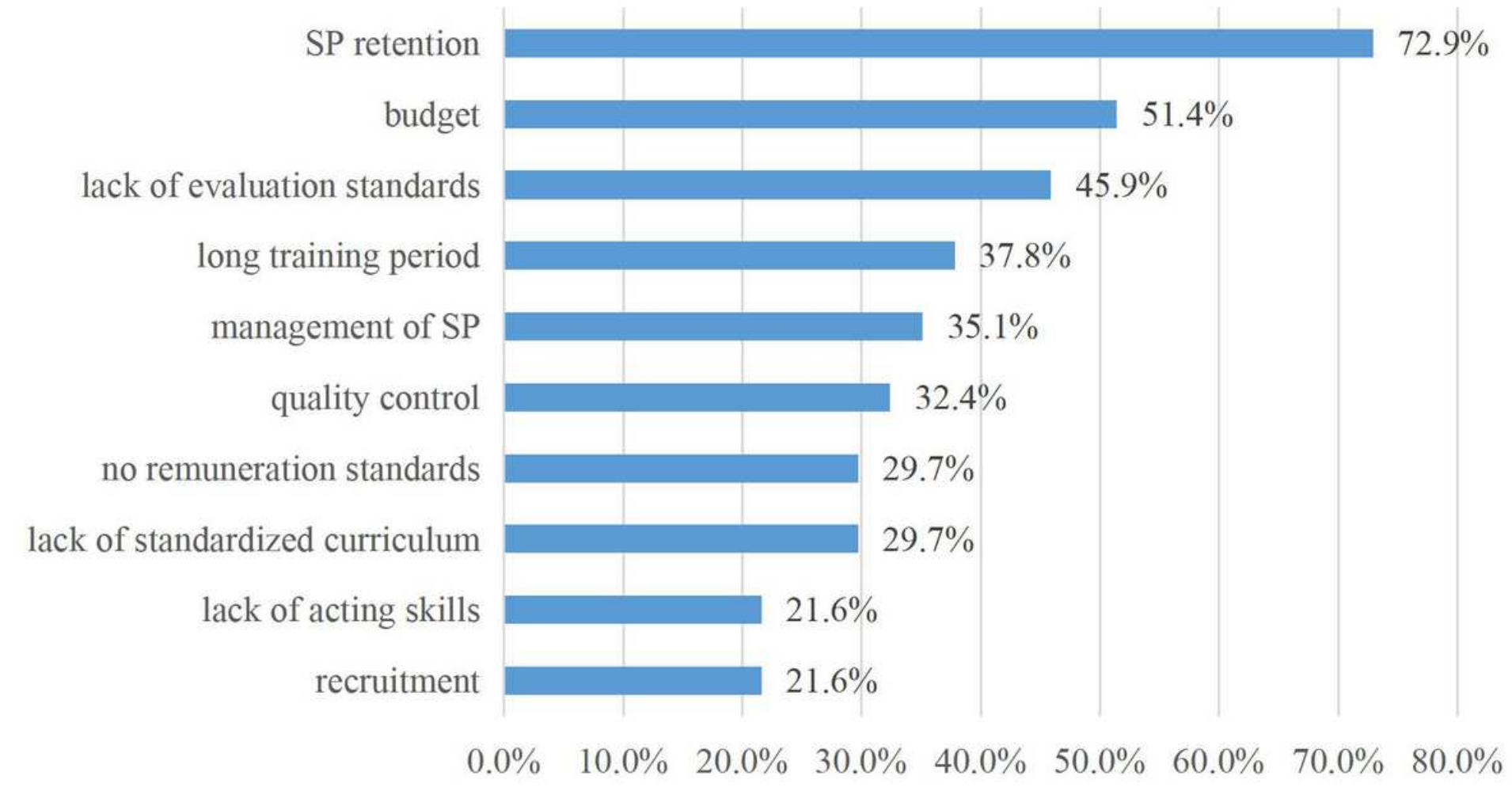

\section{Figure 4}

See image above for figure legend

Fig.5 Topics for Future Implementation( $(n=20)$

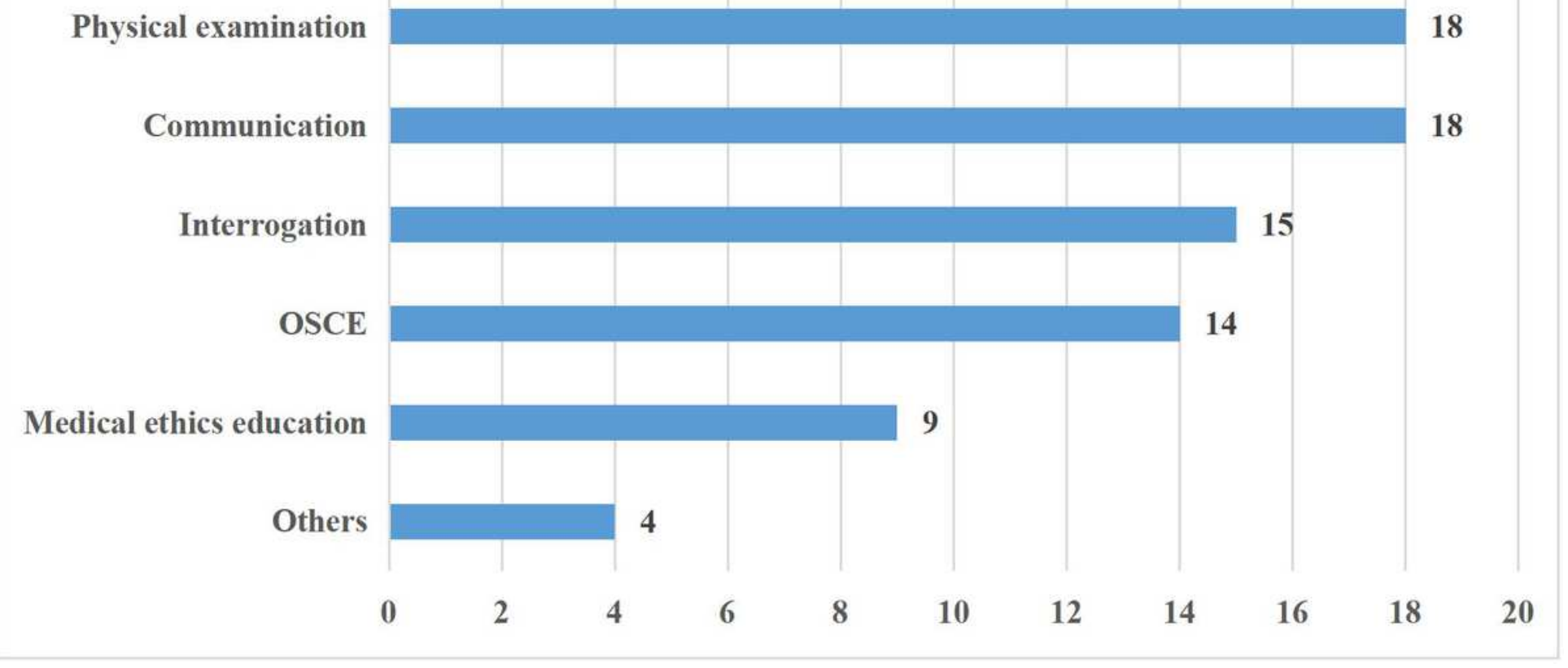


Figure 5

See image above for figure legend

\section{Supplementary Files}

This is a list of supplementary files associated with this preprint. Click to download.

- investigateandstudyinformedconcent.pdf 